\title{
CRISPR-Powered Microfluidics in Diagnostics: A Review of Main Applications
}

\author{
Mostafa Azimzadeh 1,2,3 (D), Marziyeh Mousazadeh ${ }^{4}\left(\mathbb{D}\right.$, Atieh Jahangiri-Manesh ${ }^{4}\left(\mathbb{D}\right.$, Pouria Khashayar ${ }^{5}$ \\ and Patricia Khashayar $6, *$ (D)
}

1 Department of Medical Biotechnology, School of Medicine, Shahid Sadoughi University of Medical Sciences, Yazd 89165-887, Iran; m.azimzadeh@ssu.ac.ir

2 Medical Nanotechnology \& Tissue Engineering Research Center, Yazd Reproductive Sciences Institute, Shahid Sadoughi University of Medical Sciences, Yazd 89195-999, Iran

3 Stem Cell Biology Research Center, Yazd Reproductive Sciences Institute, Shahid Sadoughi University of Medical Sciences, Yazd 89195-999, Iran

4 Department of Nanobiotechnology, Faculty of Biological Sciences, Tarbiat Modares University, Tehran 14115-111, Iran; m.mosazadeh74@yahoo.com (M.M.); a.jahangiri.m@gmail.com (A.J.-M.)

5 Institute of Cardiovascular and Medical Sciences, University of Glasgow, Glasgow G12 8QQ, UK; pouriaksr@gmail.com

6 Center for Microsystems Technology, Imec and Ghent University, 9050 Ghent, Belgium

* Correspondence: patricia.khashayar@ugent.be; Tel.: +32-9264-5565

Citation: Azimzadeh, M.; Mousazadeh, M.; Jahangiri-Manesh, A.; Khashayar, P.; Khashayar, P. CRISPR-Powered Microfluidics in

Diagnostics: A Review of Main Applications. Chemosensors 2022, 10, 3. https://doi.org/10.3390/ chemosensors 10010003

Academic Editor: Jin-Ming Lin

Received: 31 October 2021

Accepted: 20 December 2021

Published: 24 December 2021

Publisher's Note: MDPI stays neutral with regard to jurisdictional claims in published maps and institutional affiliations.

Copyright: (C) 2021 by the authors. Licensee MDPI, Basel, Switzerland. This article is an open access article distributed under the terms and conditions of the Creative Commons Attribution (CC BY) license (https:// creativecommons.org/licenses/by/ $4.0 /)$.

\begin{abstract}
In the past few years, the CRISPR (clustered regularly interspaced short palindromic repeats) applications in medicine and molecular biology have broadened. CRISPR has also been integrated with microfluidic-based biosensors to enhance the sensitivity and selectivity of medical diagnosis due to its great potentials. The CRISPR-powered microfluidics can help quantify DNAs and RNAs for different diseases such as cancer, and viral or bacterial diseases among others. Here in this review, we discussed the main applications of such tools along with their advantages and limitations.
\end{abstract}

Keywords: microfluidics; lab-on-chip; CRISPR; biosensor; medical detection

\section{Introduction}

Clustered regularly interspaced short palindromic repeats (CRISPR) is a highly precise gene-editing tool that is changing research and treatment of various diseases including cancer, blood disorders, blindness, human immunodeficiency virus (HIV), cystic fibrosis, muscular dystrophy, Huntington's disease, and COVID-19 [1-3]. CRISPR technology is a simple yet powerful tool for highly specific and rapid modification of DNA in a genome, which is the complete set of genetic instructions in an organism. In this technology, an endonuclease protein, in which a short guide RNA (sgRNA) controls its DNA-targeting specificity and cutting activity, is mainly used for gene-editing purposes. As a result, CRISPR is considered as a flexible tool that can be easily guided to target nearly any location in the genome. This versatile gene-editing system has progressed swiftly, and various utilizations from disease diagnosis to therapeutic intermediations have been supported through this method [4].

One of the reasons for its popularity is that it performs genetic engineering on an unprecedented scale possible at a very low cost. On the contrary to the previous genetic engineering techniques such as recombinant DNA technologies that allowed particular genes to be inserted into a plasmid/virus, it also allows for the introduction or removal of more than one gene at a time, facilitating rapid manipulation of different genes in a cell line, plant, or even animal/human, reducing the process time from several years to a matter of weeks [5]. It is also not species-specific, making the manipulation of organisms previously resistant to genetic engineering possible [6].

In this regard, the CRISPR/Cas9 system has revolutionized genome engineering and medicine due to its high degree of flexibility, simplicity, and accuracy in cutting and pasting 
DNA compared with other mutagenic techniques, like Zinc-finger nucleases (ZFNs) and Transcription activator-like effector nucleases (TALEN) [7]. This system mainly depends on a strand of DNA or RNA with a particular sequence binding naturally to another strand with a matching sequence. The potential off-target properties of CRISPR/Cas-edited human cell lines have been highlighted in several in vitro and in vivo studies [8]. Since it can be applied directly on embryos, for instance, CRISPR/Cas9 can reduce the time required to modify target genes compared to gene-targeting technologies based on the use of embryonic stem (ES) cells [9,10].

Although CRISPR technology has led to success in some aspects of medicine, delivery within the genome editing operating system remains challenging. The transfection of CRISPR components can often be inefficient when applying conventional delivery tools, including viral elements and chemical vectors because of the restricted packaging size and the incompetency of some cell types. Despite the high efficacy of viral vectors in gene delivery, the use of virus transmission techniques has raised concerns due to their carcinogenic and immunogenic potential [11].

Identifying new highly precise technologies to selectively modify and manipulate specific genes could, therefore, provide a powerful tool to characterize gene functions in basic research and to find potential therapeutics for genome regulation. In the past decade, microfluidic technologies have been widely implemented in many fields ranging from fundamental biological research to targeted delivery [12-14]. Gene delivery is the process of introducing an engineered pDNA (plasmid DNA), which encodes a functional, therapeutic gene to help modulate cellular functions and responses, into a nucleus. However, efficient delivery requires the pDNA to be protected; pDNA/cationic liposome (CL), in which the liposome is produced using microfluidic hydrodynamic focusing devices, is a promising strategy for non-viral gene therapy [15].

\section{CRISPR-Powered Microfluidics Applications}

One of the requirements for successful modification of the eukaryotic genome using the CRISPR/Cas9 system is the presence of the guide RNA (sgRNA or crRNA/duplex crRNA/tracrRNA) Cas 9 protein complex and the introduction of mRNA or DNA. In therapeutic approaches, the genome of specific cells can be re-transplanted into the patient in vitro and then the host genome modified to treat any possible deficiency in genes.

Nowadays, the use of microfluidic channels and chips is one of the best approaches to deliver materials and cells as it prevents many problems by accurately editing the cell and creating an opportunity for successful editing and screening of their genome [16]. Such chips provide a suitable substrate for cell manipulation, drug screening, and exosome characterization. Furthermore, they are useful for pathogen and cancer detection because of their high throughput, low cost, flexibility, and controlled fluid or gas flow [17]. In the past few years, scientists have been using the potential of CRISPR technology in diagnostics too. The spesicifc binding with very high selectivity level makes the CRISPR technology very attactive in the field of medical diagnostics [18].

Due to the low volumes required, microfluidic technologies represent a promising alternative to conventional laboratory techniques [19]. This is because they enable generic and consistent miniaturization, integration, automation, and parallelization of (bio-)chemical processes [10]. They also have great potential for complex sample processing and possible integration of the biosensors, making them robust and powerful tools in point-of-care (PoC) testing [20]. This could be a modest way to decrease the cost and turnaround time of the test while significantly reducing the handling errors and contaminations risks $[18,21]$. The new generation of microfluidics modifies nanoliter volumes of liquids or even less using interconnected micron-sized channels designed for automated delivery of stimulatory factors to the cells [22].

The applications of CRISPR-powered microfluidics in biology and medicine have been studied over the past few years. In biosensors, CRISPR helps detect the target oligonucleotide biomarkers with high selectivity and precision [23,24]. Therefore, the CRISPR- 
powered microfluidic biosensors can perform better in sensitivity, selectivity, stability, and simultaneous detection of multiple oligoes as well as the possibility of integration with or without amplification [25-28]. The system can be cheaper and sometimes automated, portable, and compatible with PoC applications $[29,30]$. These platforms have also been shown to not only increase the expression of Cas9 mRNA considerably but also in certain cases enhance the gene-editing efficiency of the system [31].

Here in this review, we provide an overview of recent CRISPR-based microfluidic biosensors. We categorize the published papers based on the biosensor applications in detecting viruses and bacteria, cancer, miRNA, DNA, and genome screening. We discuss the recent advancements, their advantages, and limitations, and future perspectives. Table 1 is overviewing the recent advances in CRISPR-powered microfluidic biosensors.

Table 1. The summary of recent CRISPR-powered microfluidic biosensors and their specifications.

\begin{tabular}{|c|c|c|c|}
\hline Analyte/Biomarker & $\begin{array}{l}\text { Components, Mechanism, } \\
\text { and Special Features }\end{array}$ & Sensitivity & References \\
\hline $\begin{array}{l}\text { RNA/DNA hybrid of } \\
\text { SARS-CoV-2 genome }\end{array}$ & $\begin{array}{l}\text { CRISPR/Cas12a, trans cleavage, catalase-ssDNA } \\
\text { probe, no amplification step, magnetic beads, } \\
\text { bubble image detection, visible readout, } \\
\text { detection time: } 71 \text { min }\end{array}$ & 50 copies per $\mu \mathrm{L}$ & [32] \\
\hline $\begin{array}{c}\text { Intact virus and RNA } \\
\text { detection of SARS-CoV-2 and } \\
\text { HIV }\end{array}$ & $\begin{array}{l}\text { Magnetic beads, platinum nanoparticles, } \\
\text { antibodies, CRISPR/dCas9, RNA extraction and } \\
\text { amplification, time: more than } 60 \mathrm{~min}\end{array}$ & $\begin{array}{l}\text { SARS-CoV-2: } 10^{3} \text { copies per } \\
\text { mL, HIV: } 250 \text { copies per mL }\end{array}$ & {$[33]$} \\
\hline $\begin{array}{c}\text { SARS-CoV-2 genome and } \\
\text { heat-inactivated SARS-CoV-2 } \\
\text { virus }\end{array}$ & $\begin{array}{l}\text { RT-RPA, CRISPR/Cas12a, Alexa647 fluorophore } \\
\text { reporter, time of RNA detection: } 15 \mathrm{~min} \text {, time of } \\
\text { inactivated virus detection: } 30 \mathrm{~min}\end{array}$ & $\begin{array}{l}\text { RNA detection: } 1 \mathrm{GE} / \mu \mathrm{L} \text {; } \\
\text { heat-inactivated detection: } \\
\qquad 20 \mathrm{GE} / \mu \mathrm{L}\end{array}$ & {$[24]$} \\
\hline SARS-CoV-2 genome & $\begin{array}{l}\text { RT-RPA, CRISPR/Cas12a, magnetic beads, } \\
\text { digital magnetofluidics device, fluorescent } \\
\text { detectors, time: } 30 \mathrm{~min}\end{array}$ & $1 \mathrm{GE}$ per $\mu \mathrm{L}$ & [29] \\
\hline SARS-CoV-2 genome & $\begin{array}{l}\text { RT-LAMP, CRISPR/Cas12, electrokinetic } \\
\text { microfluidics, isotachophoresis, ion mobility, } \\
\text { trans cleavage, time: } 30-40 \mathrm{~min}\end{array}$ & 10 copies per $\mu \mathrm{L}$ & {$[34]$} \\
\hline SARS-CoV-2 genome & $\begin{array}{l}\text { Amplification, CRISPR/Cas13, } \\
\text { two-part miniaturized device, mobile software, } \\
\text { quantify fluorescent readout, time: } 55 \mathrm{~min}\end{array}$ & 1200 copies per $\mathrm{mL}$ & {$[35]$} \\
\hline Ebola genome & $\begin{array}{l}\text { CRISPR/Cas13a, trans cleavage, } 24 \text { parallel } \\
\text { assays, no amplification, time: } 5 \mathrm{~min}\end{array}$ & $\begin{array}{c}20 \text { PFU per } \mathrm{mL}, \\
5.45 \times 10^{7} \text { copies per } \mathrm{mL}\end{array}$ & {$[36]$} \\
\hline Ebola genome & $\begin{array}{l}\text { CRISPR/Cas12a, RT-RPA, trans cleavage, } \\
\text { PEG-ssDNA, PA-DNA, } \mu \text { PAD, electronic } \\
\text { detection, AuNPs, time: within a few hours }\end{array}$ & 11 aM nucleic acid & {$[37]$} \\
\hline CCR5 gene, HIV model & $\begin{array}{l}\text { CRISPR/dCas9, ion concentration polarization, } \\
\text { ion mobility behavior, no amplification, time: } \\
100 \mathrm{~min}\end{array}$ & 3 pM DNA & {$[30]$} \\
\hline HPV16 and HPV18 genome & $\begin{array}{l}\text { CRISPR/Cas12a, dynamic aqueous multiphase } \\
\text { detection, three-chambered microfluidic, } \\
\text { RPA amplification, time: } 60 \mathrm{~min}\end{array}$ & $\begin{array}{l}\text { HPV16: } 10 \text { copies per } \mathrm{mL} \\
\text { HPV18: } 100 \text { copies per } \mathrm{mL}\end{array}$ & {$[38]$} \\
\hline $\begin{array}{l}\text { Pseudomonas aeruginosa } \\
\text { genome }\end{array}$ & $\begin{array}{l}\text { CRISPR/Cas12a, recombinase-aided } \\
\text { amplification, automated reaction, time: } 90 \mathrm{~min}\end{array}$ & $\begin{array}{c}10^{3} \text { CFU per mL, } 10 \mathrm{aM} \\
\text { nucleic acid }\end{array}$ & {$[26]$} \\
\hline Genomes of 169 viruses & $\begin{array}{c}\text { CRISPR/Cas13, PCR or RPA amplification, trans } \\
\text { cleavage, microarray chips, multiplex detection, } \\
\text { time: } 30-60 \text { min }\end{array}$ & $10^{4}$ copies per $\mu \mathrm{L}$ & [39] \\
\hline
\end{tabular}


Table 1. Cont.

\begin{tabular}{|c|c|c|c|}
\hline Analyte/Biomarker & $\begin{array}{c}\text { Components, Mechanism, } \\
\text { and Special Features }\end{array}$ & Sensitivity & References \\
\hline $\begin{array}{l}\text { Zika virus (ZIKV) and } \\
\text { Flavivirus Dengue (DENV) } \\
\text { genome }\end{array}$ & $\begin{array}{c}\text { RPA amplification, CRISPR/Cas13, trans } \\
\text { cleavage, lateral flow test, gold nanoparticles, } \\
\text { FAM reporter, time: } 90 \mathrm{~min}\end{array}$ & 2 aM RNA & {$[40]$} \\
\hline $\begin{array}{c}\text { CYP1A1*2 gene }(\mathrm{A} 4889 \mathrm{G}, \\
\text { rs1048943) }\end{array}$ & $\begin{array}{c}\text { PAM insertion by PCR amplification, centrifugal } \\
\text { microfluidic chip, simultaneous rotation, } \\
\text { and fluorescent readout with point-of-care } \\
\text { analytical instrument }\end{array}$ & $\begin{array}{c}\text { three genotypes of target } \\
\text { SNPs }\end{array}$ & {$[27]$} \\
\hline miR-19b (brain tumor marker) & $\begin{array}{l}\text { Amplification-free, CRISPR/Cas13a, } \\
\text { microfluidic sensor, amperometry readout }\end{array}$ & 10 pM LOD & {$[41]$} \\
\hline miR-19b and miRNA-20a & $\begin{array}{l}\text { Amplification-free, CRISPR/Cas13a, } \\
\text { microfluidic sensor, simultaneous multiplexed } \\
\text { detection, amperometry }\end{array}$ & $\begin{array}{l}\text { up to } 8 \text { miRNA } \\
\text { simultaneously }\end{array}$ & {$[25]$} \\
\hline
\end{tabular}

\subsection{Microfluidic CRISPR-Based Biosensors for Virus}

\subsubsection{SARS-CoV-2}

The COVID-19 pandemic pointed out the importance of rapid, accurate, and ondemand detection of viruses such as the severe acute respiratory syndrome coronavirus-2 (SARS-CoV-2). Reverse-transcription quantitative real-time polymerase chain reaction (RT-qPCR) is still the gold standard test for the detection of this positive single-stranded RNA (ssRNA) virus responsible for more than 4.8 million deaths worldwide [42]. This is while rapid detection tests based on the clustered regularly interspaced palindromic repeats of (CRISPR)/Cas proteins in combination with microfluidics are shown to be new promising approaches for pathogen detection [43].

In this regard, Silva et al. developed a cellphone-based amplification-free system with CRISPR/CAS-dependent enzymatic (CASCADE) assay (Figure 1A) [32]. After RNA extraction from nasal swabs, the prepared sample was combined with reverse transcriptase (RT) for about $10 \mathrm{~min}$ to produce RNA/DNA hybrids. Afterward, the catalase-ssDNA probe bonded to the magnetic beads, and CRISPR/Cas12 protein was added to the reaction chamber for $1 \mathrm{~h}$. Following the specific binding of CRISPR/Cas12 to the SARS-CoV-2 genome, the trans cleavage ability of Cas12a caused the cleavage of ssDNA and production of free catalase. After separating the catalase-ssDNA probes using magnetic beads, $6 \%$ hydrogen peroxidase solution was added to generate bubbles, which could be recorded by a smartphone camera. The optical signal generated by these bubbles appeared in $1 \mathrm{~min}$ and was simply and quantitatively measured by the smartphone without any need for external devices. CASCADE was capable of detecting down to 50 RNA copies per $\mu \mathrm{L}$ without any amplification; this capacity was reduced to five copies per reaction when an amplification step was added. It was concluded that CASCADE is a smartphone-based amplification-free detection platform with the minimum hardware needs. Removing the extraction step and providing an artificial intelligence (AI)-based image databank can help provide faster and more sensitive detection results.

Another smartphone-based pathogen detection resource multiplier was developed using adversarial networks (SPyDERMAN) for intact and viral nucleic acid detection [33]. The CRISPR/dCas9 protein used in this platform has catalytical inactivated cas proteins that selectively bind to the target sequence without any endonuclease activities. This platform, using a dataset library of adversarial neural network algorithms, could specifically detect five different viruses. These algorithms helped not only to standardize the shape and size of bubbles but also to reduce the differences in various phone cameras. An example of reaction fundamentals for SARS-CoV-2 will be discussed later in the paper. The microfluidic platform was made of poly (methyl methacrylate) sheets, which is a great idea for automated applications with lengthy extraction and amplification processes requiring 
smaller amounts of reagents. After RNA extraction and cDNA amplification, the mixture was added to a CRISPR/dCas9 solution. After proper incubation, platinum nanoparticles (PtNPs) bonded to monoclonal antibodies against Cas 9 and a $6 \%$ hydrogen peroxidase solution was added. Later, the gas bubbles produced by the catalase-like activity of PtNPs were photographed.

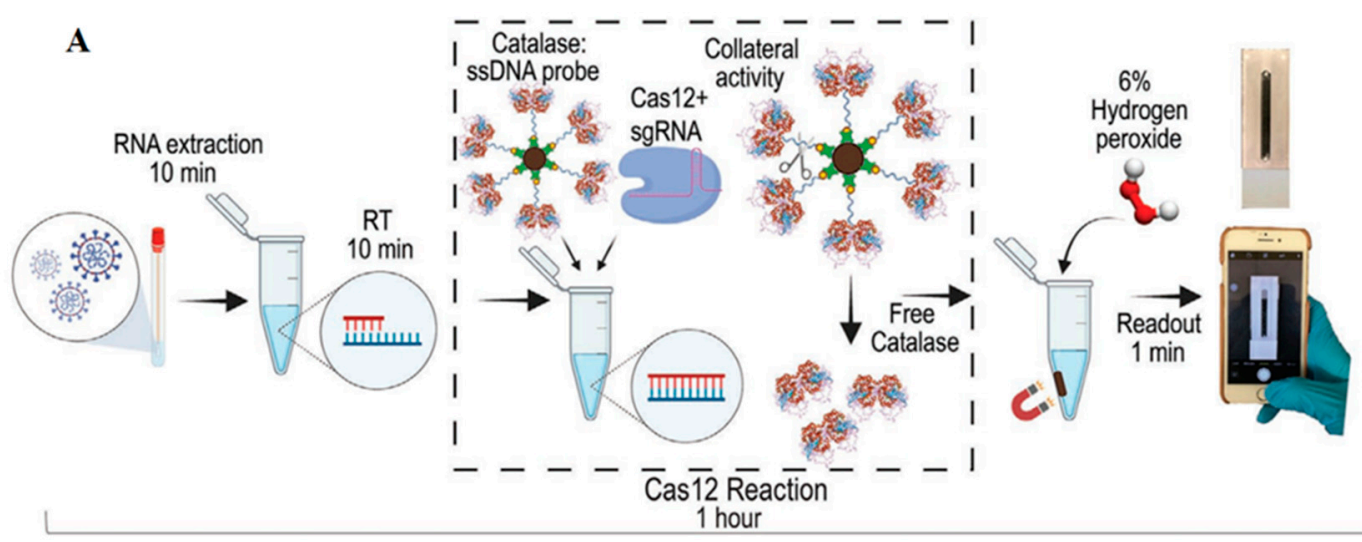

B

CASCADE Assay

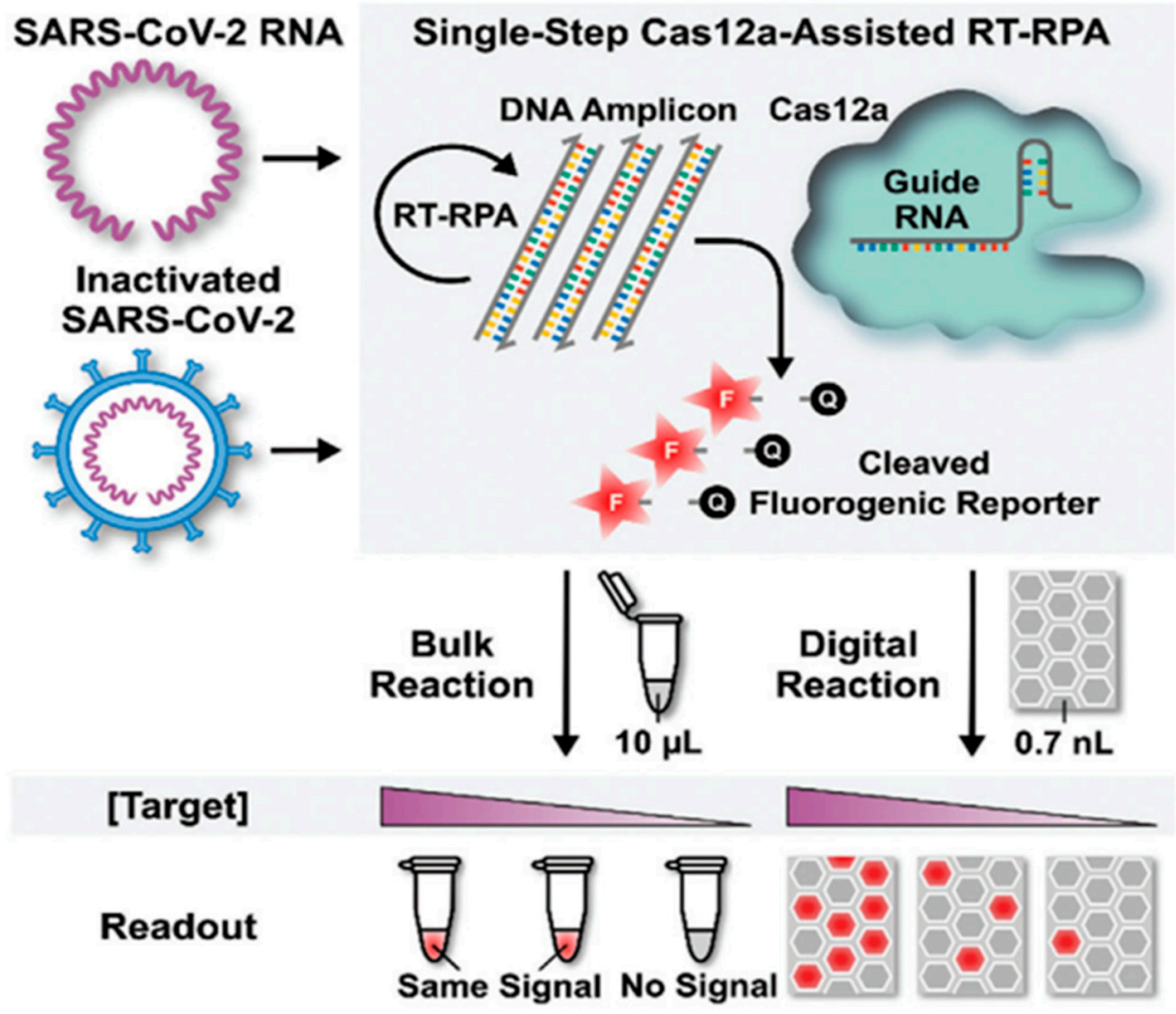

Figure 1. (A) CASCADE assay based on the trans cleavage activity of Cas12, in which the catalase enzyme produces gas bubbles for visual detection [32]. (B) deCOViD assay in which fluorophorequencher probes break after the activation of Cas12. Cas12 trans cleavage activity and the microfluidics provided the digitized fluorescent signals [24].

A new CRISPR-based sensor known as digitization-enhanced CRISPR/Cas-assisted one-pot virus detection (deCOViD) was developed by Park et al. (Figure 1B) [24]. deCOViD is based on reverse transcription and recombinase polymerase amplification (RT-RPA), which uses fluorophore probes like Alexa647. After the production of DNA amplicons, CRISPR/Cas12a specifically cleaved the target DNA so that the fluorescent signals could 
be observed. Integrating this into a digitized microfluidic chip, besides minimizing the reagents and materials, increased the reaction speed thanks to the locally high concentration of nucleic acids in the small microfluidic wells. Using RT-RPA instead of traditional RT-PCR and transforming the platform into a microfluidic platform also reduced the detection time by up to $15 \mathrm{~min}$. The system was also capable of reading the heat-inactivated virus without extracting RNA in $30 \mathrm{~min}$. Since RNA extraction and purification were no longer needed, the detection time became shorter and LOD improved. CRISPR/Cas12a with a proper crRNA used in this research was responsible for the high specificity of the sensor. deCOViD has the lowest LOD in comparison with similar CRISPR-based platforms. The LOD was reported to be one genome equivalent (GE) per $\mu \mathrm{L}$ for SARS-CoV-2 genome detection and $20 \mathrm{GE}$ per $\mu \mathrm{L}$ for the heat-inactivated SARS-CoV-2 samples.

A novel SARS-CoV-2 POC, introduced by Chen et al., composed of miniaturized magnetic arms, fluorescent detector, and heating module (Figure 2A) [29]. The sensor known as POC-CRISPR worked in three main steps. Firstly, a nasopharyngeal swab was inserted into an elution tube containing detergent and magnetic beads buffers. The detergent caused virus decomposition and then the negatively-charged RNAs bonded to the positively-charged magnetic beads. Next the solution was transferred to the working cartridge and was placed in the droplet magneto-fluidic (DM) device, where the extraction, purification, and concentration processes happened all together. In this step, the magnetic beads separated the RNAs from other cell lysates and concentrated them by moving them to a new area in the microfluidic device. Following these processes, the purified RNA was produced using the RT-RPA and DNA amplicons. In this step, fluorescent signals were generated when fluorophore probes were released through DNA cleavage by the CRISPR/Cas12a. The signals were then detected by the DM device, and signals were wirelessly sent to a cellphone. The microprocessors embedded in the DM device accelerated this step. The POC-CRISPR was reported to have an acceptable LOD (1 GE per $\mu \mathrm{L})$, require a low $(100 \mu \mathrm{L})$ starting solution, and have a short duration of less than $30 \mathrm{~min}$. In this system, the magnetic beads acted as the fundamentals for RNA purification and concentration along with shortening the purification time; they also enhanced the sensitivity thanks to their concentrating ability. Therefore, their applicability in high-tech sensors to increase the performance of CRISPR-based assays, especially in microfluidic devices, was shown.

Electrokinetic microfluidic sensor coupled with CRISPR/Cas12 and reverse transcriptionloop-mediated isothermal amplification (RT-LAMP) is another example (Figure 2B) [34]. This sensor was modified for SARS-CoV-2 detection using isotachophoresis (ITP) technique and an electrokinetic microfluidic chip. First, ITP-based ion mobility was generated in the microchannel embedded in the chip. The coexistence of a high-mobility leading (LE) and a low-mobility trailing (TE) buffer in a microfluidic channel resulted in different ion mobility in the sample following the application of an electric field. This phenomenon caused negatively charged nucleic acids to be fully separated from other parts of a cell lysate. After the nucleic acid separation and purification steps in a nasopharyngeal sample, the SARS-CoV-2 RNA genome was transformed into cDNA using the RT-LAMP system in the chip. After the amplification process, CRISPR/Cas12 specifically recognized the target sequence. Then ssDNA, which was attached to a fluorophore and a quencher, was cleaved by the trans cleavage ability of the CRISPR/Cas12 protein. By separating the fluorophore and the quencher pair, the fluorescent signals representing the desired genome, this process happened in 30-40 min with an LOD of 10 copies per $\mu \mathrm{L}$. Automated reagent mixing, need for a low amount of reagents, and accurate detection are the main advantages of this sensor.

Puig et al. developed a fluorescent sensor called miSHERLOCK (minimally instrumented SHERLOCK). It worked based on the trans cleavage ability of the CRISPR/Cas13 [35]. This specific enzymatic test was implemented in a miniatured device that extracted and concentrated the viral RNA, needed for SARS-CoV-2 detection, in the saliva samples. The device consisted of two parts. In the first part, the saliva sample was inserted, and then the RNA molecules were extracted and concentrated using polyethersulfone (PES) membrane. After this step, the concentrated RNA met the CRISPR/Cas13 enzyme and other 
related cocktail factors in the second part of the two-chambered holder containing the fluorescent laser. Around $1 \mathrm{~h}$ later, the device was connected to a mobile as the fluorescent readout. This platform could detect three different variants of SARS-CoV-2 successfully with an average LOD of 1200 copies per $\mathrm{mL}$ for the universal variant. Albeit the sensitive and smart idea behind the miSHERLOCK, the need for $4 \mathrm{~mL}$ of saliva sample and the 55 -min reaction time were among its shortcomings.

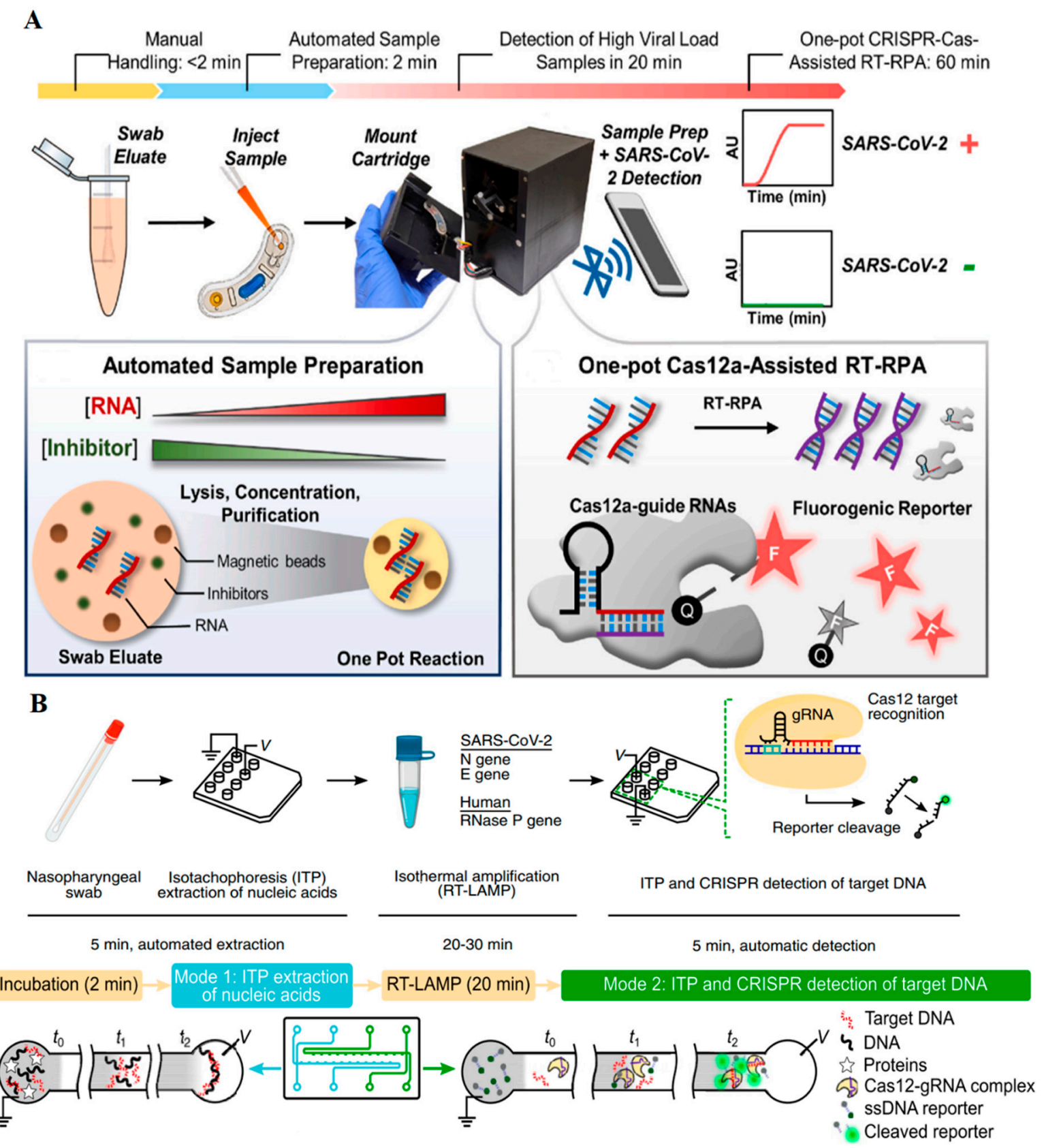

Figure 2. (A) POC-CRISPR assay with droplet microfluidics, in which RNAs are separated and concentrated using electrostatistical attachment to magnetic beads and fluorescent signals again using Cas12 trans cleavage [29]. (B) An electrokinetic microfluidic chip that creates isotachophoresis mobility in the microfluidic device for RNA separation and sensitivity enhancement [34].

\subsubsection{Ebola Virus}

Ebola is a deadly virus from the Filoviridae family with a negative ssRNA genome. It was responsible for a deadly outbreak of a hemorrhagic fever syndrome between the 
years 2013 and 2020 [44]. While sequencing and PCR methods are the main detection methods of Ebola virus, POC devices with a need for minimum reagents and inexpensive materials seem to be required for possible future endemics.

A POC sensor for Ebola detection based on the CRISPR/Cas13a trans cleavage ability was developed by Qin et al. [36]. In this attempt, a microfluidic chip with 24 parallel assays for the Ebola RNA and CRISPR-crRNA combinations was fabricated. During the free-amplification process, CRISPR/Cas13a-crRNA targeted the Ebola genome and after Cas13 activation, due to the trans cleavage ability of the Cas protein, the quenched RNA probes were cleaved, resulting in fluorescent signals. The reported LOD was $5.45 \times 10^{7}$ copies per $\mathrm{mL}$ in $5 \mathrm{~min}$. The inexpensive POC sensor needed low sample volume. The short detection time, little background signals, and the free-amplification process were among its advantages. The high cross-reactivity reported in this platform could be due to the off-targets of CRISPR/Cas13a, and could be reduced by developing recombinant Cas's proteins with fewer off-targets.

Smart nucleic acid response materials [PEG hydrogel with ssDNA linkers (PEGssDNA) and polyacrylamide hydrogel with DNA linkers (PA-DNA)] could also be fabricated for this purpose. PEG-ssDNA hydrogels absorb fluorophores and enzymes, while PA-DNA hydrogels entrap gold nanoparticles (AuNPs) and cells. When CRISPR/Cas12a proteins in the hydrogel structure meet the target sequence, their trans cleavage activity breaks the DNA linkers, changing the morphology of the hydrogels. It also results in the release of the fluorophores bonded to the linkers or entrapped AuNPs, producing color signals. Based on these fundamentals, a paper-based microfluidic system ( $\mu$ PAD) was fabricated for Ebola detection [37]. The target genome was amplified by RT-RPA and inserted into the $\mu \mathrm{PAD}$ with embedded hydrogels. Based on the lateral flow (LF) mobility of the reaction molecules, different signals were obtained. The color- (fluorescent signals for the fluorophores, and visual ones for the AuNPs), electric- (by combining the $\mu \mathrm{PAD}$ system with an electrode-based chip for conductivity measurement), and visual microscopy(morphological changes of hydrogels) based signals are various output signals leveraged from the described microfluidic system. Although the sensor could detect the Ebola genome at concentrations as low as $11 \mathrm{aM}$, the hydrogel alteration process was time-consuming and thus the response signals only appeared after a few hours, which is not suitable for rapid detection tests. Furthermore, due to the sensitivity of CRISPR/Cas proteins to temperature, this material may not work properly for long hours at room temperature.

\subsubsection{Human Immunodeficiency (HIV)}

HIV is a positive ssRNA virus that belongs to the Retrovirus family. The virus causes human acute immunodeficiency syndrome (AIDS) and has been responsible for a global pandemic with almost 30 million deaths during the past four decades. Although lifelong antiretroviral therapy (ART) is still its main treatment, there is still no efficient drug or vaccine on the market. As a result, fast and reliable detection methods remain crucial for such widespread syndrome to reduce its complications [45].

A sensor for C-C chemokine receptor type 5 (CCR5) gene detection related to the human immunodeficiency virus (HIV) was developed as a model by Lee et al. (Figure 3A) [30]. This gene expresses one of the most important entry receptors for HIV. The sensor contained a microfluidic platform with a microchannel creating ion concentration polarization (ICP). The detection process in the sensor was based on different mobility behaviors monitored by fluorophores. Following the ICP generation in the microchannels and based on different hydrodynamic behavior of negatively charged moieties that are targeted DNA in this case, two different mobility behaviors were reported. In the presence of free DNA (non-target sequence) in the microchannel, the propagation mobility behavior was reported. This is while the stacking mobility was observed in the presence of DNA-CRISPR/dCas9 (target sequence), which was later coupled with fluorophores (FAM and cy3). The sensor was able to detect $3 \mathrm{pM}$ DNA in $100 \mathrm{~min}$ by a $18.4 \mathrm{pM} / \mathrm{min}$ concentration rate. It, however, has not been tested on real physiological samples, as the development of proper ICP in such 
complex samples may be challenging or affected by different factors. Moreover, unbalanced DNA and CRISPR/dCas9 molar ratios (for example, in the presence of very low or very high amounts of target DNA in the sample) could lead to false-negative and overload responses, respectively. Additionally, the preconcentration process reported along with the stacking behavior overcame the need for amplification in this sensor.
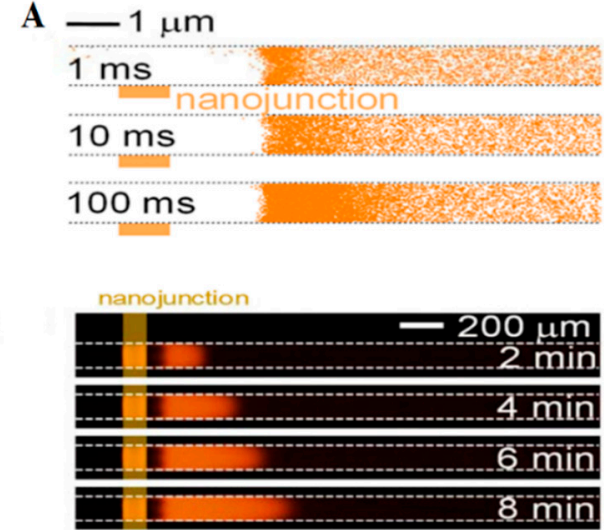
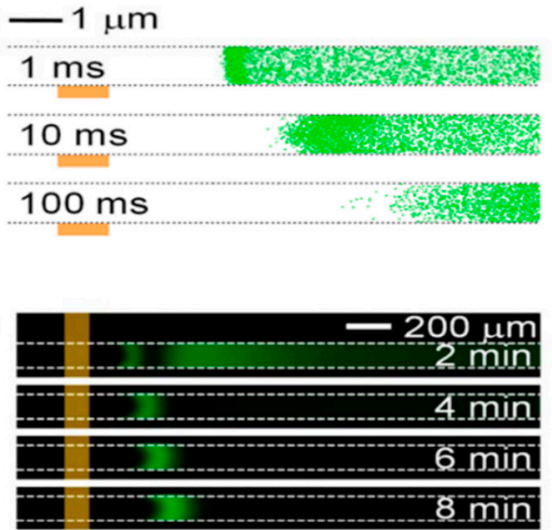

B

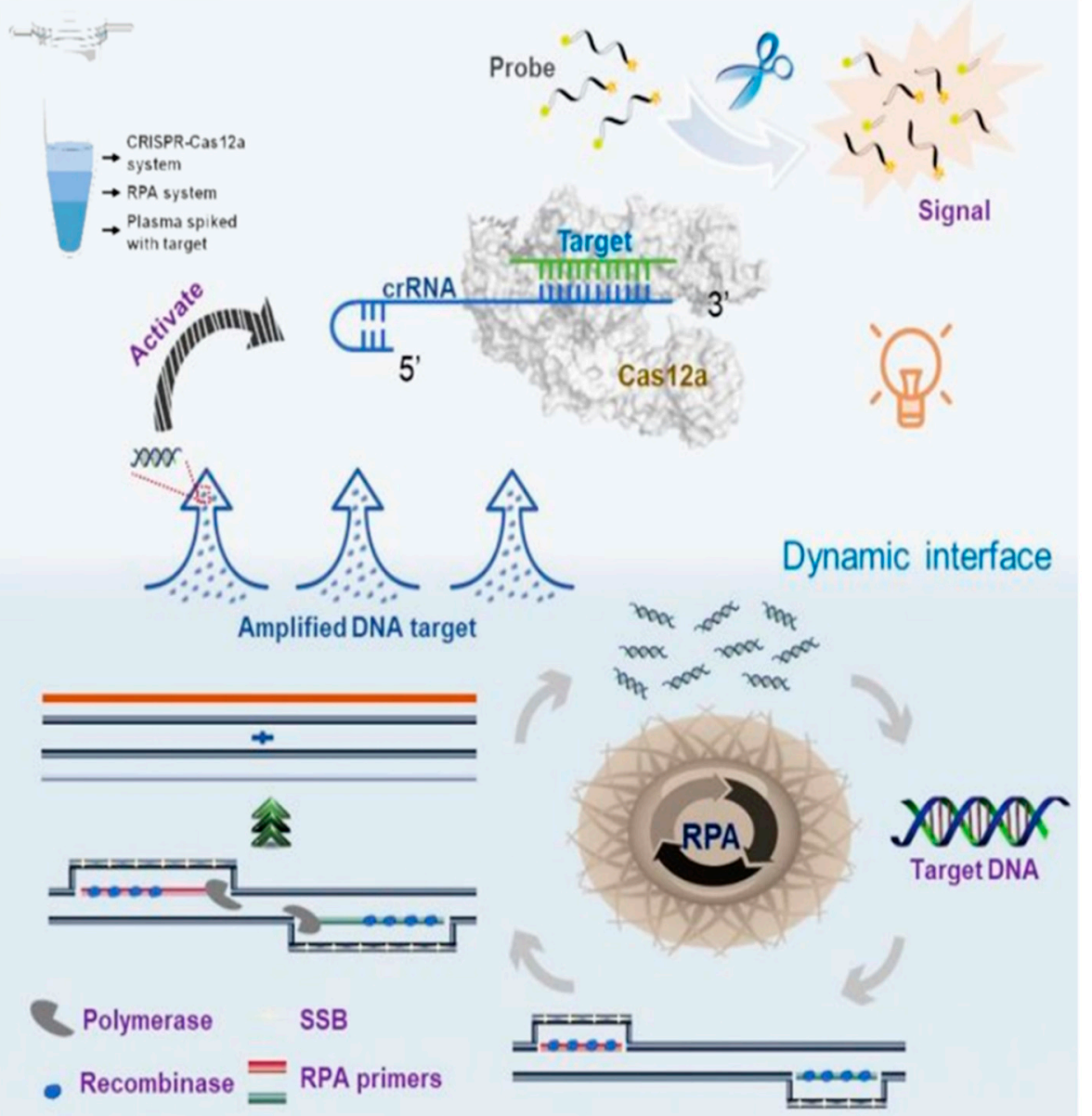

Figure 3. (A) The microfluidic platform with a microchannel creating ion concentration polarization (ICP) shows two different mobility behaviors of bound and unbound DNA-CRISPR complexes. Green and orange colors represent the stacking and propagation mobility behaviors, respectively [30]. (B) The DAMR platform represents the dynamic diffusion of cleaved nucleic acid products after Cas12 trans cleavage activity through the multiphase sucrose solutions with different concentrations [38]. 


\subsubsection{Human Papillomavirus (HPV)}

HPV is a circular double-stranded DNA widespread virus with nearly 200 subtypes. HPV infects basal epithelial cells, leading to certain cancers such as cervical cancer. More than $90 \%$ of cervical cancers are believed to be HPV related. HPV16 and HPV18 are the most common subtypes, mainly detected through sequencing or PCR methods [46]. Despite the approval of a vaccine against HPV, early detection using rapid and non-invasive methods is still needed and yet challenging.

In an attempt by Yin et al., a POC device consisted of a three-chambered-microfluidic chip and a dynamic aqueous multiphase reaction (DAMR) system conjugated with RPA (for amplification), and CRISPR/Cas12a (for selective detection) was developed (Figure 3B) [38]. The dynamic aqueous multiphase was generated using different sucrose concentrations: DNA sample in the $40 \%$ sucrose concentration in the bottom phase, RPA reagent in $10 \%$ sucrose in the middle phase, and CRISPR/Cas12a with fluorophore-quencher DNA probes in the top phase. In this regard, DNA was dynamically diffused from the bottom phase (with higher sucrose concentrations) to the top one (with lower sucrose concentrations). It was amplified in the middle phase with RPA before being diffused to the third phase, where the fluorescent signals appeared thanks to the trans cleavage properties of CRISPR/Cas12a. In this phase, the fluorophores were released from the fluorophore-quencher probes following the selective DNA binding to the crRNA. This sensor detected HPV16 and HPV18 with 10 and 100 copies per $\mathrm{mL}$, respectively, in $1 \mathrm{~h}$. The use of multiphase dynamic mobility reduced the reaction time by about 100 times compared with the single-phase reaction methods. This novel multiplex sensor was easily fabricated. Pretreatment steps like extraction and purification, however, are still needed for real samples.

\subsection{Microfluidic CRISPR-Based Biosensors for Bacteria Detection}

CRISPR-based sensing devices are also investigated in bacteria detecting sensors. In an attempt, Chen et al. developed a sensor for Pseudomonas aeruginosa genome detection (Figure 4A) [26]. This bacterium, which exists in the endothelial layers, is responsible for several illnesses in humans. The fundamental detection principle of Cas12a-assisted microfluidic equipment for nucleic acid analysis (CASMEAN) is the generation of fluorescent signals after the trans cleavage of fluorophore probes and the cis cleavage of the target genome by CRISPR/Cas12a. All the required reagents were freeze-dried in the microfluidic disc under nitrogen gas for long storage possibilities. The centrifugal microfluidic disc used in this system consisted of a polymethyl methacrylate (PMMA) layer with 32 reaction chambers and was surrounded by two sealing membranes. When a sample was loaded onto the disc, the reactions happened automatically. Firstly, the DNA genome was amplified by the recombinase-aided amplification (RAA) process and then CRISPR/Cas12a trans cleavage caused the production of fluorescent signal in the same chamber. The logic behind this phenomenon was the amplicons being rapidly cleaved by the CRISPR/Cas12a before enough trans cleavage happened. In this way, the sensitivity was low as the amplification and detection parts were not separated. It should be noted that the RAA protected the enzymatic structure of the CRISPR/Cas12a protein more than PCR and LAMP methods due to its lower and more stable thermal cycles. Furthermore, the concentration of CRISPR/Cas12a in the chamber was optimized to reduce the risk of amplicons deterioration and improve the sensor's sensitivity. The sensor was reported to have a low LOD (10 aM or $103 \mathrm{PFU} / \mathrm{mL}$ ) with a $90 \mathrm{~min}$ turnaround time. Besides its low LOD, being fully automated and requiring low amounts of sample and reagents were other advantages for this sensor. 
A
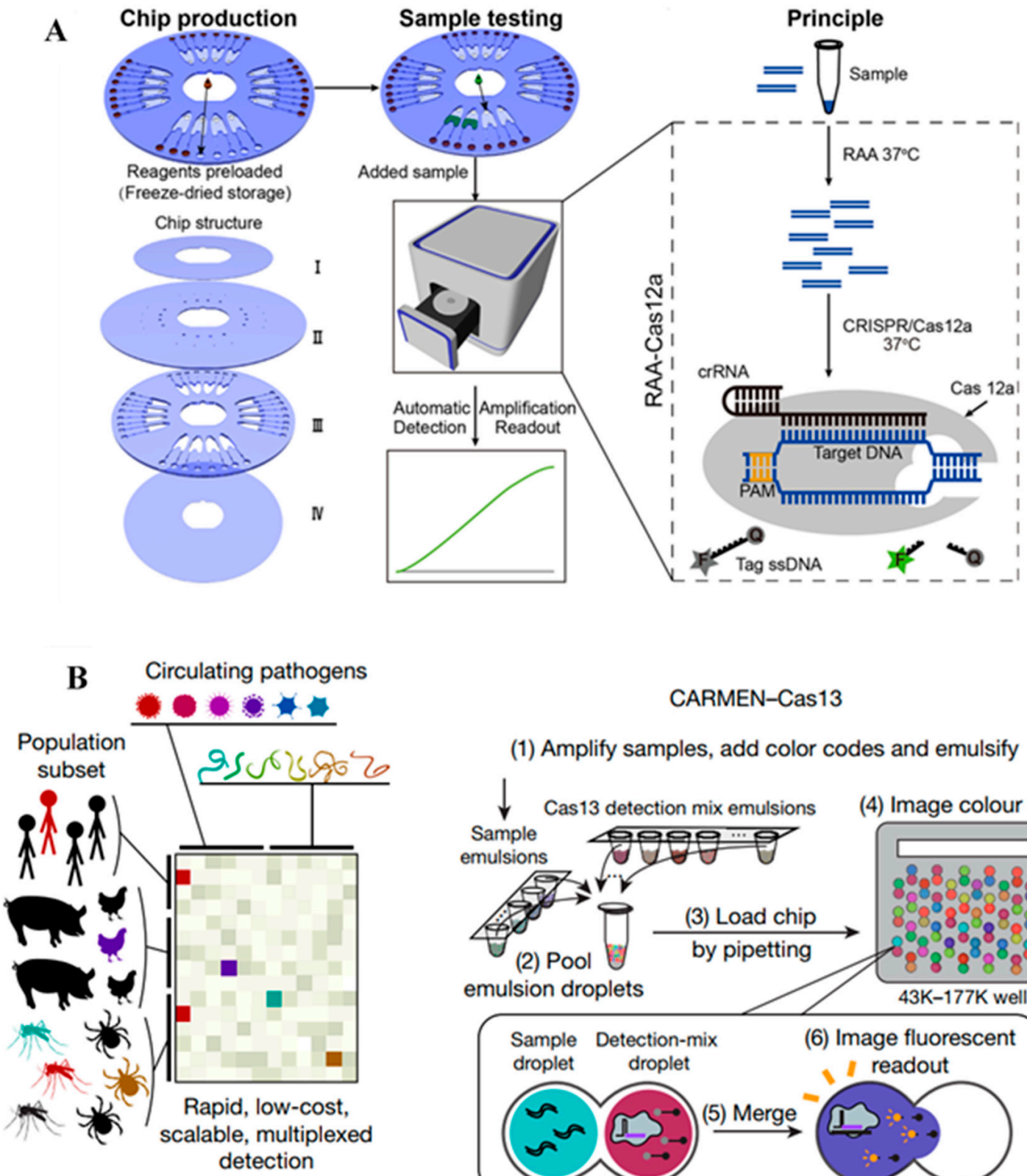

\section{CARMEN-Cas13}

(1) Amplify samples, add color codes and emulsify

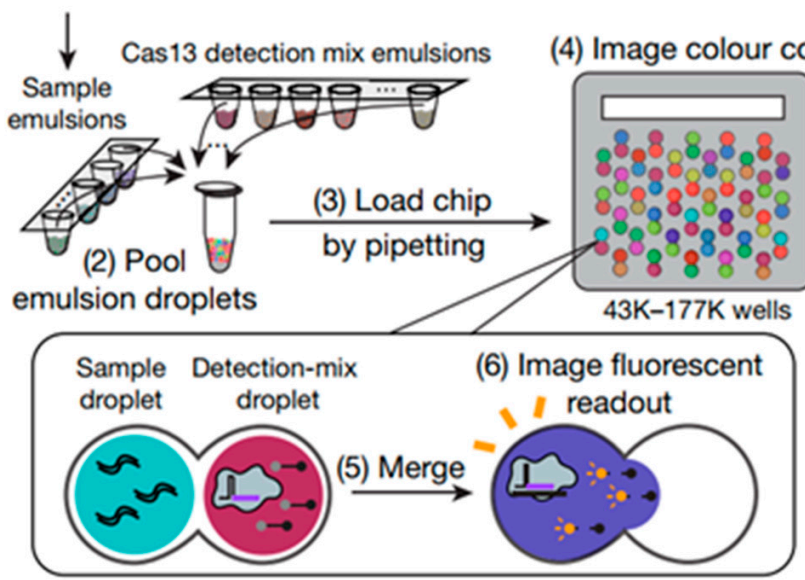

Figure 4. (A) The CASMEAN assay with a centrifugal microfluidic disc containing the freeze-dried CRISPR/Cas12 for long-term applications and fluorescent signal readouts [26]. (B) The CARMEN multiplex detection assay for 169 viruses is based on the colored map analysis created by four commercial fluorophores and Cas13 trans cleavage in a microarray chip [39].

\subsection{Microfluidic CRISPR-Based Biosensors for Multiple Species}

Combinatorial arrayed reactions for multiplexed evaluation of nucleic acids (CARMEN) combined with the CRISPR/Cas13 was developed by Ackerman et al. for the detection of a wide range of viruses (Figure 4B) [39]. In this attempt, the desired viral genomes were amplified using suitable primers with PCR or RPA methods. Then, the amplified samples were inserted into the same pool and combined. The prepared samples and droplets containing CRISPR/Cas13 with reporter probes were thereafter injected into the microarray microfluidic chip. Afterwards, the two droplets (amplified samples and CRISPR/Cas13 with reporter probes) were combined in all possible paired formats. The microfluidic chip was made of polydimethylsiloxane (PDMS) using soft lithography and provided an array for simultaneous detection of thousands of viral genomes. Reporter 
probes were made of four available commercial fluorophores, which could generate about 1050 different colors. The high number of colors led to different colored maps in the microarray chip under fluorescent microscopy. Computational biology and color algorithm interpretation techniques were key in this detection platform, which could perform massive detection (around 4500 tests) in a single chip. The low cross-reactivity with high reliability observed in the chip may be due to the highly selective nature of the used CRISPR systems and the monitoring system, which reduced the chance of error in each array. The smallest nucleic acid used in the sensor was reported to be $10^{4}$ copies per $\mu \mathrm{L}$. Besides being capable of detecting 169 viral genomes, different Influenza A subtypes and HIV mutants were also distinguished with this tool. This shows the accurate detection ability of the sensor even for small changes and variants. This platform was also used for the detection of newborn pathogens such as SARS-CoV-2, enabling the possibility of rapid adaptations to new targets.

Zika (ZIKV) and Dengue (DENV) viruses have been considered as global health emergencies by the world health organization (WHO) since 2016. They both have a positive ssRNA genome, belonging to the Flavivirus genus, and are responsible for mild to severe symptoms. Zika causes Guillain-Barré syndrome and is associated with microcephaly, while Dengue virus causes mild to hemorrhagic fever [47]. New insights in to PoC detection of these two viruses using the microfluidic-based CRISPR will be discussed here.

A LF nucleic acid detection test was developed by Gootenberg et al. [40]. SHERLOCK (specific high sensitivity enzymatic reporter unlocking) was designed to detect the ssRNA genome of Zika and Dengue viruses through trans cleavage activity of CRISPR/Cas13. After RNA amplification using RPA, the sample was loaded on a LF assay, where these two viruses were detected at 2 aM under $90 \mathrm{~min}$. The reported LF consisted of sample, control, test, and absorption pads. When the sample was loaded on the assay paper, the trans activity of CRISPR broke the nucleotide link between the FAM and biotin in the presence of the targeted RNA. Then they were exposed to the anti-FAM antibody conjugated with AuNPs on the test pad. In the absence of the target RNA, the AuNP-conjugated antibody bound to FAM and then to the control band via the biotin-streptavidin connection. In this regard, few FAM remained available for the second band to be seen. In the presence of the target RNA, the nucleotide link between the biotin and FAM broke, and the FAM reporters bonded to the second band along with the AuNP-conjugated antibody, resulting in a red-colored band. Furthermore, the self-fluorescence properties of the FAM reporter were also traceable.

\subsection{Microfluidic CRISPR-Based Biosensors for Single Nucleotide Polymorphisms (SNPs)}

Single nucleotide polymorphisms (SNPs) are heritable nucleotide variations in the DNA sequence, and are involved in various cancers. Existing SNP detection methods lack automation and satisfactory sensitivity; they are, thus, not economical for broad usage. CRISPR-based detection platforms could be promising alternatives especially if their limitations such as Cas-enzymes' PAM dependency or the challenges of heterozygous mutations detection are overcome. Chen et al. proposed PAM sequence insertion into the upstream of the SNP sites (by PCR amplification), followed by the application of two crRNAs for heterozygote determination along with complementary ssDNA removal (using excess forward primers) followed by a new nucleotide mismatch introduction (to increase signal/noise ratio), as a solution for the aforementioned challenges [27]. The platform determined the wild, heterozygous, and homozygous mutant types of the target model gene simultaneously. Freeze-dried mixed reagents (Cas12a nuclease, tag sequence, and the crRNAs) were preloaded on a centrifugal microfluidic chip, and a point-of-care analytical instrument (for simultaneous rotation and fluorescent readout) was used to reduce any external interference (Figure 5A). The results showed that the PCR-based PAM insertion is a promising solution to widen the application of CRISPR-based techniques; the whole procedure, however, might be time consuming and require various temperature settings. 
$\mathbf{A}$

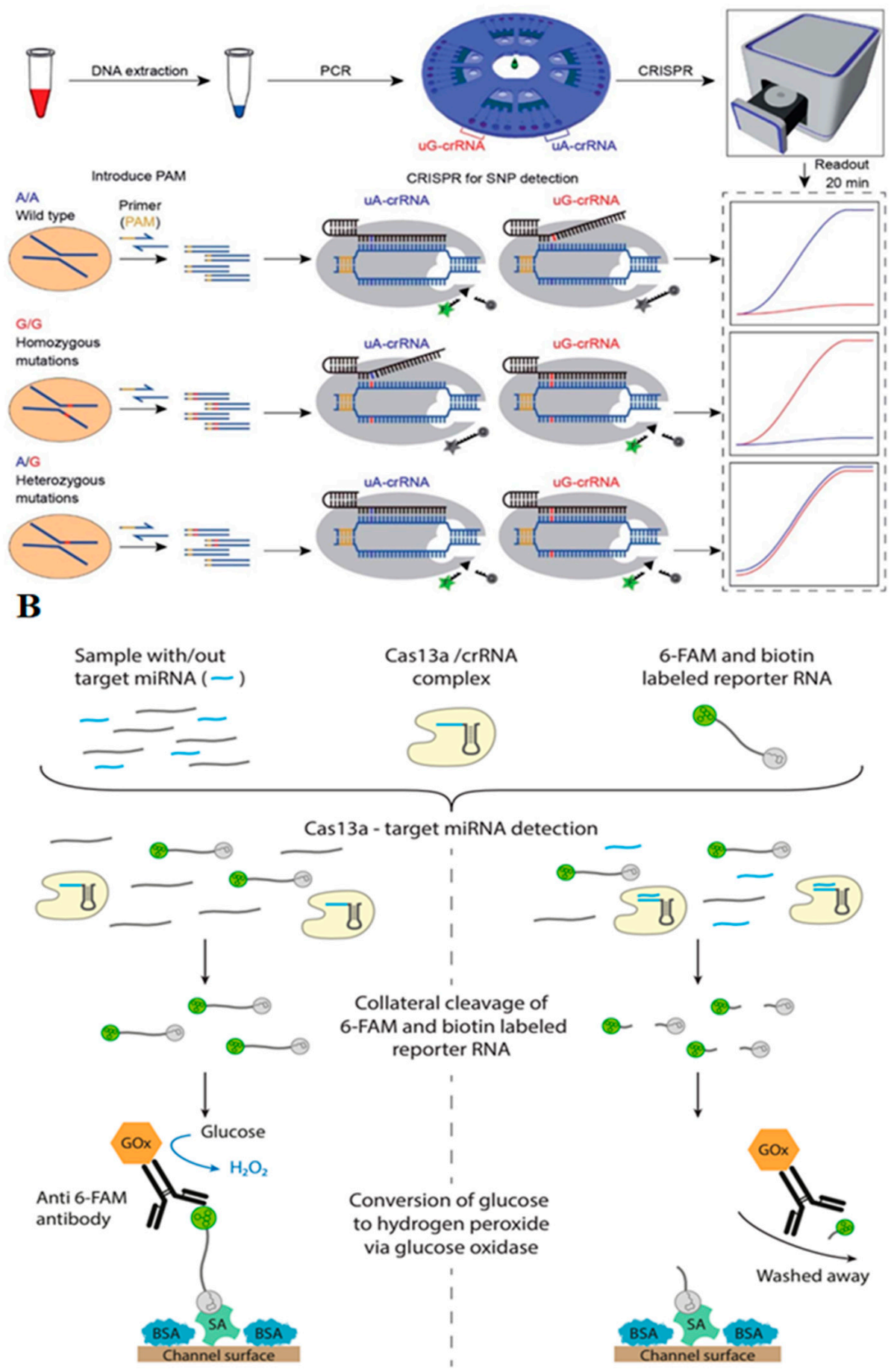

Figure 5. (A) Schematic illustration of CRISPR-based SNP detection chip [27]. (B) CRISPR-based miRNA detection for electrochemical signal readout [25].

\subsection{Microfluidic CRISPR-Based Biosensors for miRNA Quantification}

The short, non-coding oligonucleotides known as microRNAs (miRNAs) are responsible for regulating many processes through affecting their target messenger RNAs (mRNAs). Body fluids including blood, saliva, and cerebrospinal fluid are the main sources of the miRNAs. The common limitations for miRNA diagnosis include the need for amplification, complicated preparation steps, and difficulties in primer designs. 
A combination of microfluidics and electrochemical-based signal readouts with CRISPR/ Cas13a was proposed by Bruch et al. for this application [41]. The sensor owed its selectivity to the crRNA effect on the Cas13a enzyme and its sensitivity to the self-signal amplification due to time dependency of collateral reporter cleavage. The sensor comprised of a microfluidic chip with two sections: (1) the immobilization region (pre-functionalized with streptavidin and blocked with bovine serum albumin (BSA), where the cleaved and uncleaved reporter RNAs bonded, and the glucose oxidase was also immobilized using uncleaved reporters); and (2) the electrochemical cell (where the enzymatically produced $\mathrm{H}_{2} \mathrm{O}_{2}$ was detected in an amperometry manner). First, the signal was amplified by elongating the incubation time of the reagents (Cas13a, crRNAs, and reporter-RNAs) and the target sample, resulting in reporter-RNAs cleavage before they were applied on the chip. The signal was further amplified by an automatic stop-flow method of applying glucose solution on the chip, which resulted in $\mathrm{H}_{2} \mathrm{O}_{2}$ being pumped to the electrochemical detection part. The generated amperometry peak was inversely proportional to the target concentration. A satisfactory selectivity and LOD of $10 \mathrm{pM}$ was achieved following a 3-h incubation time.

Later on, Bruch et al. improved their CRISPR/Cas13a-based electrochemical sensor for multiplexed miRNA quantification using a single channel comprising sequential incubation regions (Figure 5B) [25]. This is because a single miRNA was never proved to be sufficient for the precise diagnosis of a disease, and thus, the quantification of several miRNAs simultaneously is needed. The solution resulted in the reduction of the working electrodes, bubble formation, and better fluid control (essential when the current signal is dependent on the flow rate). The CRISPR-based detection design and the $\mathrm{H}_{2} \mathrm{O}_{2}$ amperometry readout were similar to their previous work (Bruch et al. 2019). Although the result demonstrated a good LOD and efficiency, the overall process took about $4 \mathrm{~h}$, which is challenging.

\subsection{Microfluidic CRISPR-Based Cell Labeling and Sorting Assay}

Single-cell analysis of the heterogenous cell populations is vital for precise diagnosis and therapeutic purposes. While most of the methods for studying single cells are applicable for pure cultures, microfluidic platforms provide high throughput single cell assessment with adequate local condition control. However, the isolation and assessment of rare cells remain a challenge. This inspired Labib et al. to develop a microfluidic platform for cell ranking by labeling the cells of interest with magnetic nanoparticles and sorting them using an external magnetic force with a special design [48]. The platform named "magnetic ranking cytometry" or MagRC for short, not only did not affect the integrity or the viability of the cells, but also was not susceptible to $\mathrm{pH}$, temperature, or surrounding ionic conditions. There were two generations of MagRC, each with different design and application. The first design was for the isolation and assessment of scarce cell populations such as circulating tumor cells, stem cells, or pathogenic organisms. Figure 6A illustrates the first generation used for the detection of stem cells among a population of differentiated cardiomyocytes. Following the labeling of the target cells with magnetic nanoparticles, they were sorted into eight regions. The cells were used for further immunostaining and imaging studies [49].

The second MagRC design was appropriate for sorting the cells expressed in a specific protein, especially in CRISPR phenotypic screening in large cell populations. Figure 6B depicts this design, which divides the cells into 10 parts using the counteraction between the magnetic and drag forces [50].

Identification of the regulator genes for phenotypic factors and the modulators of important protein expressions is valuable for the investigation of novel and effective therapeutic methods. Using the second design and an immunomagnetic-mediated cell sorting, Mair et al. applied genome-wide CRISPR screening for identifying genetic regulators of the phenotypic factor CD47 [51]. The expression of this cell-surface protein prevents the cells from phagocytes. Thus, blocking its interaction with target proteins in macrophages is a potential cancer treatment strategy. The application of CRISPR/Cas9 to genetically 
modify cells helped them induce the desired changes with appropriate precision in the microfluidic platforms. It also helped them increase the throughput and cell viability and reduce the assay time and expenses. FACS (fluorescence-activated cell sorting), despite being the gold standard for cell isolation and sorting, suffers from inadequate throughput and low cell viability.

A

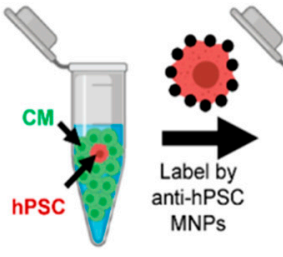

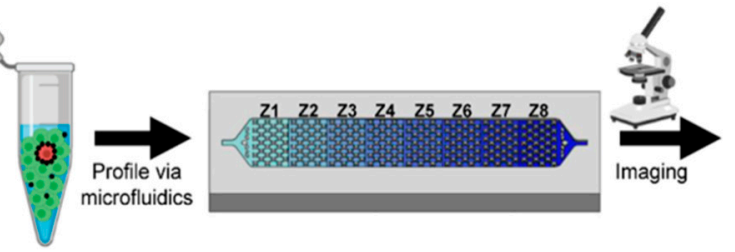
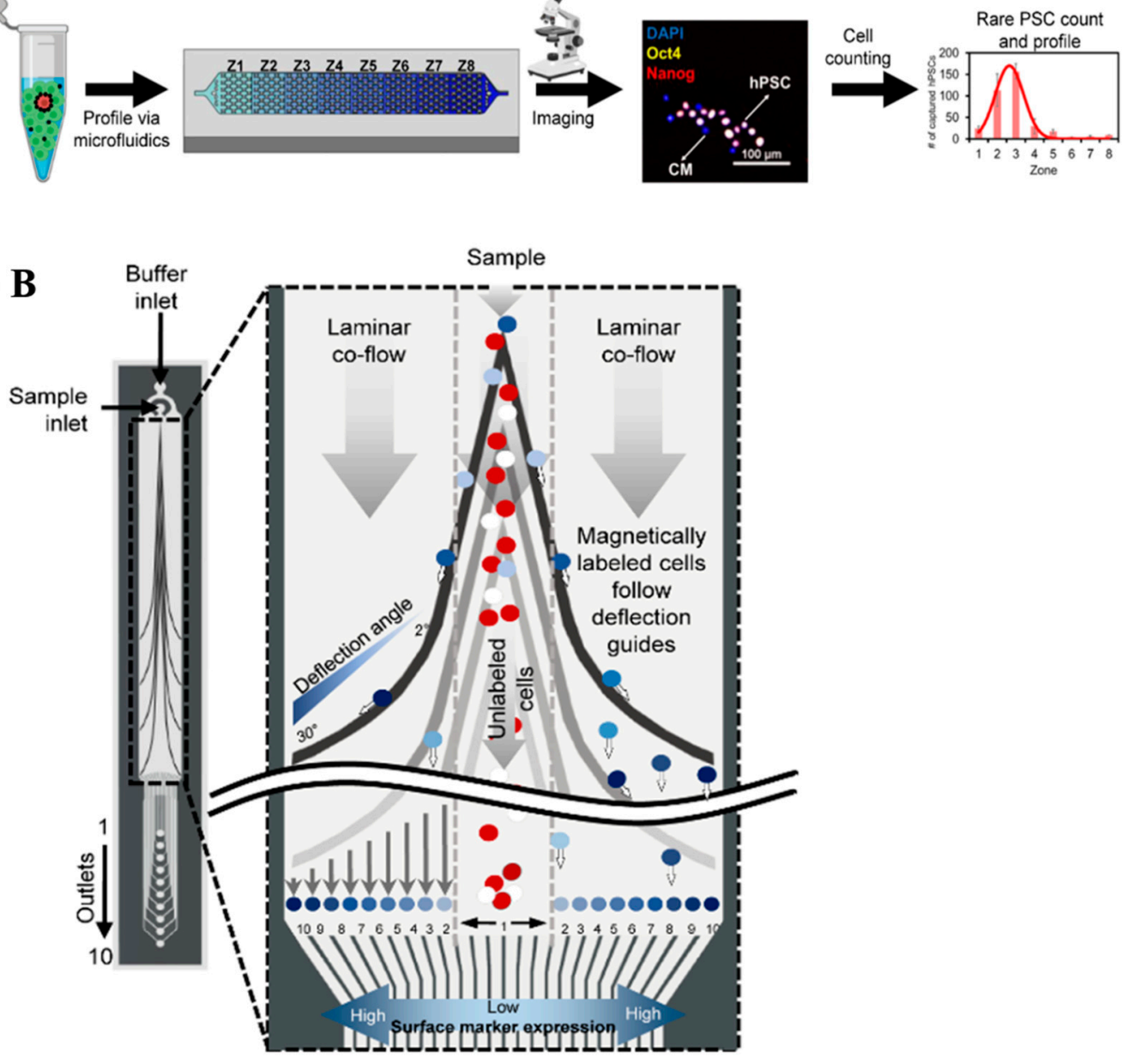

Figure 6. (A) Stem cell isolation and sorting with first-generation MagRC device and nanoparticles [49]. (B) Schematic representation of second-generation MagRC design for cell sorting [50]. It should be noted that while this design is not CRISPR based, the same technology is applied in the CRISPR-based versions.

\subsection{Microfluidic CRISPR-Based in Genomics Studies}

Microfluidics CRISPR-based platforms have been used in the past couple of years for large-scale functional genetic screening and identification of the genes responsible for morphological or behavioral phenotypes [52]. Apart from this, CRISPR technology has provided a precise, efficient, and specific novel gene-editing method with potential application for gene therapy purposes in a wide range of organisms from plants to humans. However, there are concerns about its accuracy and off-target possible consequences. Although some off-target variations such as single nucleotide variations (SNVs), indels, and duplications are detectable, distant off-target unintended variations are usually uncommon and undetectable. Variations in the vicinity of the large target regions such as reintegration (possible when two gRNAs are applied), deletion, and indel happen during the repair process of double-strand breakages. Currently, there are several molecular assessment methods for the verification of gene editing accuracy, although they fail to explore distant regions from the 
target site alterations. Focusing on the challenge, Blondal et al. managed to introduce a new microfluidic technique for indirect sequence capture, called Simplix Xdrop ${ }^{\circledR}$. This could enrich large target fragments $(\sim 100 \mathrm{~kb})$ more than 100-fold (Figure 7) [23]. Their method comprised of two amplification parts: (1) amplification of a small amplicon located within or near the target region (gene-edited site for example) by droplet PCR in double-emulsion droplets, followed by analysis and sorting using a flow cytometer and the release of long DNA parts, containing the target region from the droplets. (2) Amplification of sequences with a target region trapped in single-emulsion droplets by so-called "multiple displacement amplification in droplets (dMDA)" method. The resulting amplified fragments were further used in short and long-read sequencing methods. The application of their indirect capture design allowed the use of primers designed for several kilobases further from the main target region to avoid long indels and detect large deletions.

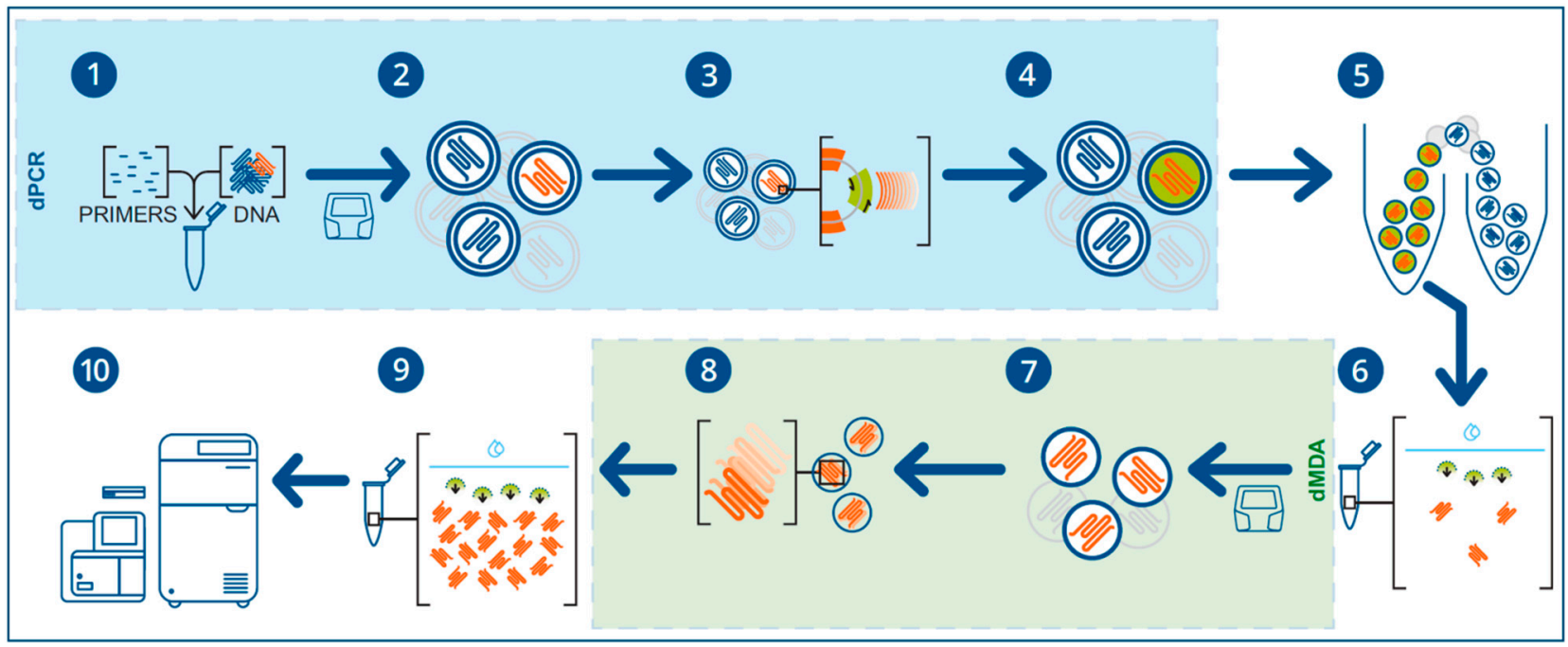

Figure 7. Schematic illustration of the steps of the microfluidic technique for indirect sequence capture (Samplix Xdrop ${ }^{\circledR}$ ) [23].

There are natural oscillations in the biochemical reactions of the living organisms controlling biological processes such as cell divisions and cell cycle. Genetic oscillators, as one of the synthetic genetic circuits, are designed to control gene expression dynamics and the timing of the engineered processes, like bacteria cell lysis time for in-vivo delivery purposes. The "repressilator" is a seminal genetic oscillator applied in three repressors (LacI, TetR, and $\lambda$-cI), each repressing the other in a negative feedback loop [53]. The dynamic features of the loop introduced by Elowitz et al. were later assessed to improve the circuit designs. A newly introduced method for gene regulation, based on replacing transcription factors-based methods, is CRISPR interference (CRISPRi). In this technique, a catalytically inactivated Cas9 enzyme (dCas9) is used. Henningsen et al. introduced a so-called "Rock Paper CRISPR" (RPC) as a hybrid method, replacing one of the transcriptional repressors of repressilator by CRISPRi [54]. Using this approach, they managed to achieve stable temporal fluctuations to monitor 100 bacteria in a microfluidic machine. Although the integration of the two approaches made deliberate control of the genome functions possible by using suitable sgRNAs, challenges of the off-target binding of dCas 9 and the slow rate of function of the platform remained.

Genetic circuits are also used for designing growth switches, aiming to enhance cell factories for the production of a higher number of the metabolites of interest (proteins or biochemicals) rather than growth and replication. The application of CRISPR technology has advantages such as being fast and flexible and not needing the deletion of vital genes. $\mathrm{Li}$ et al. used CRISPR as a switch for bacterial growth to block nucleotides production and prevent chromosomes replication while keeping the metabolite production intact [55]. 
A microfluidic system was also used for tracking the cells at the single-cell level and assessing the functionality of the system. They tested four different targets to separate bacteria production from the growth and observed an increase in both GFP expression as a model protein (2.2-fold) and mevalonate as a model metabolite (41\% yield increase), while cell growth was suppressed.

A precise application of genome editing tools requires a comprehensive, high resolution, and controlled study of the live cell phenotypes, using advanced microscopy and microfabrication technologies. However, the determination of the role of unknown genes requires the study of pool-synthesized genetic libraries of several strains, simultaneously. Hence, Camsund et al. developed a microfluidic-based method called DuMPLING (dynamic $\mu$-fluidic microscopy phenotyping of a library before in situ genotyping) for both phenotyping with high resolution and genotyping of several strains on the same chip [56]. Using this microfluidic chip, each strain with an unknown genotype occupied a specific region. The chip also helped prolong the bacterial exponential growth state for several generations, making the high-resolution phenotypic study of phase-contrast imaging of the cells possible. As for genotype determination, the cells were fixed on the chip and the genotype was deduced using fluorescence in situ hybridization (FISH) with a barcode. DuMPLING steps are: (1) bacteria in CRISPRi library with plasmids expressing sgRNA for a particular gene and a barcode; (2) loading the cell library on the microfluidic chip, occupation of a determined location by each strain, and long-time cell imaging; and (3) cell fixation, barcode-based genotyping with the FISH method. Although DuMPLING is a good candidate for the identification of key regulating genes in cell cycles, the method still suffers from the off-target binding of sgRNAs and its impact on cell morphology remains as a challenge.

Single-cell level study of bacterial cells, besides helping with the investigation of the regulatory genes, can help human beings face microbial challenges like Antimicrobial Resistance (AMR) phenomena, making precise genetic and physiological observations possible. Current efforts to deal with AMR include attempts to improve the antibiotics' efficiency or investigate new targets for antimicrobial materials, alongside advanced engineering methods, devices, and technologies like synthetic biology. Since a big driving factor in AMR is the heterogenicity in the bacterial population, high throughput screening methods are necessary. An automated microfluidic-based method for long-time $(10 \mathrm{~h})$ observation of phenotypic alterations in E. coli exposed to ampicillin and the assessment of the minimum inhibitory concentration (MIC) was later proposed by Kong et al. [57]. The replacement of silicon or polymeric material with inexpensive alternatives such as agarose membrane reduces the fabrication costs and the need for the modification of an ordinary microscope with additional software script and hardware parts, facilitating the observation of real-time and long bacterial phenotypic changes. Therefore, the platform could be used for studying single cells' exposure to a gradient concentration of materials and assessing the effects. The proposed method was also suitable for the application of CRISPRi-induced inhibition of cells' division, controlling dCas9 in stable inducers' concentrations.

CRISPR/Cas9-mediated high throughput microfluidic platforms are introduced as suitable methods for large-scale genetic assessments. The genes involved in important biological events such as resistance to drugs or generation of metastatic behavior in tumors were identified using the CRISPR/Cas9 method. Han et al. employed the CRISPR/Cas9 knockout method for gene deletion and developed microfluidic chips for high population cell sorting to study kinases involved in tumor suppression. It was based on the known fact that high cell deformability is proportional to tumor initiation and metastasis potential [58]. The CRISPR-manipulated cells were sorted based on their mechanical properties by the microfluidic design, which trapped the stiff healthy cells and passed the soft deformed ones. The cells were then sequenced to identify kinases, whose loss was the driving factor behind cell deformability. Microfluidic-based cell sorting methods are high throughput and label-free and are helpful in saving time and costs. They also provide the possibility of single-cell level precise observations and high-resolution cell sorting. In addition, their 
combination with CRISPR-based genetic manipulation methods provides a promising platform for efficient, accurate, and high throughput, as well as fast and cost-effective genetic screening.

\section{Conclusions}

In this review, we summarized the recent advancements in microfluidic platforms using CRISPR technology in biomedical diagnostics. This strategy combined the advantages of microfluidics and CRISPR, resulting in more sensitive, selective, and fast diagnostics. In the past couple of years, the number of applications for such platforms has increased vastly, ranging from biosensors for bacteria and viruses to cancer diagnosis and miRNA quantification. We showed that these platforms can solve many of the challenges faced by current diagnostics and improve their performance. Despite all these attempts, such platforms still suffer from shortcomings mainly due to off-target properties of CRISPR/Cas and long sample preparation times; thus, future work is expected to address these issues along with expanding their applications.

On the other hand, microfluidics have also improved genome screening and editing using CRISPR-based genetic manipulation methods. This combination has provided a promising future for efficient, accurate, and high throughput, as well as fast and costeffective genetic screening. This is because, unlike conventional methods, CRISPR is more controlled, can help affect several genes at the same time and at a shorter time, and the microfluidic platform improves cell sorting and selection while improving the efficacy of the system.

Author Contributions: Writing-original draft preparation, M.A., P.K. (Pouria Khashayar), M.M. and A.J.-M.; editing and supervision, P.K. (Patricia Khashayar). All authors have read and agreed to the published version of the manuscript.

Funding: This research received no external funding.

Institutional Review Board Statement: Not Applicable.

Informed Consent Statement: Not Applicable.

Data Availability Statement: Not Applicable.

Conflicts of Interest: The authors declare no conflict of interest.

\section{References}

1. Cyranoski, D. Chinese scientists to pioneer first human CRISPR trial. Nature 2016, 535, 476-477. [CrossRef] [PubMed]

2. Brooks, A.K.; Gaj, T. Innovations in CRISPR technology. Curr. Opin. Biotechnol. 2018, 52, 95-101. [CrossRef]

3. Adli, M. The CRISPR tool kit for genome editing and beyond. Nat. Commun. 2018, 9, 1911. [CrossRef] [PubMed]

4. Li, H.; Yang, Y.; Hong, W.; Huang, M.; Wu, M.; Zhao, X. Applications of genome editing technology in the targeted therapy of human diseases: Mechanisms, advances and prospects. Signal Transduct. Target. Ther. 2020, 5, 1. [CrossRef] [PubMed]

5. Komaroff, A.L. Gene Editing Using CRISPR: Why the Excitement? JAMA 2017, 318, 699-700. [CrossRef] [PubMed]

6. Han, H.A.; Pang, J.K.S.; Soh, B.-S. Mitigating off-target effects in CRISPR/Cas9-mediated in vivo gene editing. J. Mol. Med. 2020, 98, 615-632. [CrossRef] [PubMed]

7. Gaj, T.; Gersbach, C.A.; Barbas III, C.F. ZFN, TALEN, and CRISPR/Cas-based methods for genome engineering. Trends Biotechnol 2013, 31, 397-405. [CrossRef] [PubMed]

8. Wu, H.; Chen, X.; Zhang, M.; Wang, X.; Chen, Y.; Qian, C.; Wu, J.; Xu, J. Versatile detection with CRISPR/Cas system from applications to challenges. TrAC Trends Anal. Chem. 2021, 135, 116150. [CrossRef]

9. Whitesides, G.M. The origins and the future of microfluidics. Nature 2006, 442, 368-373. [CrossRef] [PubMed]

10. Mark, D.; Haeberle, S.; Roth, G.; von Stetten, F.; Zengerle, R. Microfluidic lab-on-a-chip platforms: Requirements, characteristics and applications. Chem. Soc. Rev. 2010, 39, 1153-1182. [CrossRef]

11. Peyravian, N.; Malekzadeh Kebria, M.; Kiani, J.; Brouki Milan, P.; Mozafari, M. CRISPR-Associated (CAS) Effectors Delivery via Microfluidic Cell-Deformation Chip. Materials 2021, 14, 3164. [CrossRef] [PubMed]

12. Melin, J.; Quake, S.R. Microfluidic Large-Scale Integration: The Evolution of Design Rules for Biological Automation. Annu. Rev. Biophys. Biomol. Struct. 2007, 36, 213-231. [CrossRef] [PubMed]

13. Buckner, R.L.; Krienen, F.M.; Castellanos, A.; Diaz, J.C.; Yeo, B.T.T. The organization of the human cerebellum estimated by intrinsic functional connectivity. J. Neurophysiol. 2011, 106, 2322-2345. [CrossRef] [PubMed] 
14. Sackmann, E.K.; Fulton, A.L.; Beebe, D.J. The present and future role of microfluidics in biomedical research. Nature 2014, 507, 181-189. [CrossRef] [PubMed]

15. Balbino, T.A.; Azzoni, A.R.; de la Torre, L.G. Microfluidic devices for continuous production of pDNA/cationic liposome complexes for gene delivery and vaccine therapy. Colloids Surf. B Biointerfaces 2013, 111, 203-210. [CrossRef]

16. Zhang, B. CRISPR/Cas gene therapy. J. Cell. Physiol. 2021, 236, 2459-2481. [CrossRef]

17. Song, K.; Li, G.; Zu, X.; Du, Z.; Liu, L.; Hu, Z. The Fabrication and Application Mechanism of Microfluidic Systems for High Throughput Biomedical Screening: A Review. Micromachines 2020, 11, 297. [CrossRef]

18. Haji Mohammadi, M.; Mulder, S.; Khashayar, P.; Kalbasi, A.; Azimzadeh, M.; Aref, A.R. Saliva Lab-on-a-chip biosensors: Recent novel ideas and applications in disease detection. Microchem. J. 2021, 168, 106506. [CrossRef]

19. Halldorsson, S.; Lucumi, E.; Gómez-Sjöberg, R.; Fleming, R.M.T. Advantages and challenges of microfluidic cell culture in polydimethylsiloxane devices. Biosens. Bioelectron. 2015, 63, 218-231. [CrossRef]

20. Xu, L.; Shoaie, N.; Jahanpeyma, F.; Zhao, J.; Azimzadeh, M.; Al-Jamal, K.T. Optical, electrochemical and electrical (nano)biosensors for detection of exosomes: A comprehensive overview. Biosens. Bioelectron. 2020, 161, 112222. [CrossRef]

21. Khodamoradi, M.; Rafizadeh Tafti, S.; Mousavi Shaegh, S.A.; Aflatoonian, B.; Azimzadeh, M.; Khashayar, P. Recent Microfluidic Innovations for Sperm Sorting. Chemosensors 2021, 9, 126. [CrossRef]

22. Sinha, H.; Quach, A.B.V.; Vo, P.Q.N.; Shih, S.C.C. An automated microfluidic gene-editing platform for deciphering cancer genes Lab Chip 2018, 18, 2300-2312. [CrossRef]

23. Blondal, T.; Gamba, C.; Møller Jagd, L.; Su, L.; Demirov, D.; Guo, S.; Johnston, C.M.; Riising, E.M.; Wu, X.; Mikkelsen, M.J.; et al. Verification of CRISPR editing and finding transgenic inserts by Xdrop indirect sequence capture followed by short- and long-read sequencing. Methods 2021, 191, 68-77. [CrossRef]

24. Park, J.S.; Hsieh, K.; Chen, L.; Kaushik, A.; Trick, A.Y.; Wang, T.H. Digital CRISPR/Cas-Assisted Assay for Rapid and Sensitive Detection of SARS-CoV-2. Adv. Sci. 2021, 8. [CrossRef] [PubMed]

25. Bruch, R.; Johnston, M.; Kling, A.; Mattmüller, T.; Baaske, J.; Partel, S.; Madlener, S.; Weber, W.; Urban, G.A.; Dincer, C. CRISPRpowered electrochemical microfluidic multiplexed biosensor for target amplification-free miRNA diagnostics. Biosens. Bioelectron. 2021, 177. [CrossRef]

26. Chen, Y.; Mei, Y.; Zhao, X.; Jiang, X. Reagents-Loaded, Automated Assay that Integrates Recombinase-Aided Amplification and Cas12a Nucleic Acid Detection for a Point-of-Care Test. Anal. Chem. 2020, 92, 14846-14852. [CrossRef] [PubMed]

27. Chen, Y.; Mei, Y.; Jiang, X. Universal and high-fidelity DNA single nucleotide polymorphism detection based on a CRISPR/Cas12a biochip. Chem. Sci. 2021, 12, 4455-4462. [CrossRef]

28. Phaneuf, C.R.; Seamon, K.J.; Eckles, T.P.; Sinha, A.; Schoeniger, J.S.; Harmon, B.; Meagher, R.J.; Abhyankar, V.V.; Koh, C.Y. Ultrasensitive multi-species detection of CRISPR-Cas9 by a portable centrifugal microfluidic platform. Anal. Methods 2019, 11, 559-565. [CrossRef]

29. Chen, F.-E.; Lee, P.-W.; Trick, A.Y.; Park, J.S.; Chen, L.; Shah, K.; Mostafa, H.; Carroll, K.C.; Hsieh, K.; Wang, T.-H. Point-of-care CRISPR-Cas-assisted SARS-CoV-2 detection in an automated and portable droplet magnetofluidic device. Biosens. Bioelectron. 2021, 190, 113390. [CrossRef]

30. Lee, H.; Choi, J.; Jeong, E.; Baek, S.; Kim, H.C.; Chae, J.H.; Koh, Y.; Seo, S.W.; Kim, J.S.; Kim, S.J. DCas9-mediated Nanoelectrokinetic Direct Detection of Target Gene for Liquid Biopsy. Nano Lett. 2018, 18, 7642-7650. [CrossRef] [PubMed]

31. Li, X.; Feng, Q.; Han, Z.; Jiang, X. Enhancing gene editing efficiency for cells by CRISPR/Cas9 system-loaded multilayered nanoparticles assembled via microfluidics. Chin. J. Chem. Eng. 2021, 38, 216-220. [CrossRef]

32. Silva, F.S.R.; Erdogmus, E.; Shokr, A.; Kandula, H.; Thirumalaraju, P.; Kanakasabapathy, M.K.; Hardie, J.M.; Pacheco, L.G.C.; Li, J.Z.; Kuritzkes, D.R.; et al. SARS-CoV-2 RNA Detection by a Cellphone-Based Amplification-Free System with CRISPR/CASDependent Enzymatic (CASCADE) Assay. Adv. Mater. Technol. 2021. [CrossRef]

33. Shokr, A.; Pacheco, L.G.C.; Thirumalaraju, P.; Kanakasabapathy, M.K.; Gandhi, J.; Kartik, D.; Silva, F.S.R.; Erdogmus, E.; Kandula, H.; Luo, S.; et al. Mobile Health (mHealth) Viral Diagnostics Enabled with Adaptive Adversarial Learning. ACS Nano 2021, 15, 665-673. [CrossRef] [PubMed]

34. Ramachandran, A.; Huyke, D.A.; Sharma, E.; Sahoo, M.K.; Huang, C.; Banaei, N.; Pinsky, B.A.; Santiago, J.G. Electric field-driven microfluidics for rapid CRISPR-based diagnostics and its application to detection of SARS-CoV-2. Proc. Natl. Acad. Sci. USA 2020, 117, 29518-29525. [CrossRef] [PubMed]

35. de Puig, H.; Lee, R.A.; Najjar, D.; Tan, X.; Soeknsen, L.R.; Angenent-Mari, N.M.; Donghia, N.M.; Weckman, N.E.; Ory, A.; Ng, C.F.; et al. Minimally instrumented SHERLOCK (miSHERLOCK) for CRISPR-based point-of-care diagnosis of SARS-CoV-2 and emerging variants. Sci. Adv. 2021, 7. [CrossRef] [PubMed]

36. Qin, P.; Park, M.; Alfson, K.J.; Tamhankar, M.; Carrion, R.; Patterson, J.L.; Griffiths, A.; He, Q.; Yildiz, A.; Mathies, R.; et al. Rapid and Fully Microfluidic Ebola Virus Detection with CRISPR-Cas13a. ACS Sens. 2019, 4, 1048-1054. [CrossRef]

37. Gayet, R.V.; de Puig, H.; English, M.A.; Soenksen, L.R.; Nguyen, P.Q.; Mao, A.S.; Angenent-Mari, N.M.; Collins, J.J. Creating CRISPR-responsive smart materials for diagnostics and programmable cargo release. Nat. Protoc. 2020, 15, 3030-3063. [CrossRef]

38. Yin, K.; Ding, X.; Li, Z.; Zhao, H.; Cooper, K.; Liu, C. Dynamic Aqueous Multiphase Reaction System for One-Pot CRISPR-Cas12aBased Ultrasensitive and Quantitative Molecular Diagnosis. Anal. Chem. 2020, 92, 8561-8568. [CrossRef]

39. Ackerman, C.M.; Myhrvold, C.; Thakku, S.G.; Freije, C.A.; Metsky, H.C.; Yang, D.K.; Ye, S.H.; Boehm, C.K.; Kosoko-Thoroddsen, T.S.F.; Kehe, J.; et al. Massively multiplexed nucleic acid detection with Cas13. Nature 2020, 582, 277-282. [CrossRef] 
40. Gootenberg, J.S.; Abudayyeh, O.O.; Kellner, M.J.; Joung, J.; Collins, J.J.; Zhang, F. Multiplexed and portable nucleic acid detection platform with Cas13, Cas12a, and Csm6. Science 2018, 360, 439-444. [CrossRef]

41. Bruch, R.; Baaske, J.; Chatelle, C.; Meirich, M.; Madlener, S.; Weber, W.; Dincer, C.; Urban, G.A. CRISPR/Cas13a-Powered Electrochemical Microfluidic Biosensor for Nucleic Acid Amplification-Free miRNA Diagnostics. Adv. Mater. 2019, 31, 1905311. [CrossRef]

42. Chung, Y.-S.; Lee, N.-J.; Woo, S.H.; Kim, J.-M.; Kim, H.M.; Jo, H.J.; Park, Y.E.; Han, M.-G. Validation of real-time RT-PCR for detection of SARS-CoV-2 in the early stages of the COVID-19 outbreak in the Republic of Korea. Sci. Rep. 2021, $11,14817$. [CrossRef] [PubMed]

43. Ganbaatar, U.; Liu, C. CRISPR-Based COVID-19 Testing: Toward Next-Generation Point-of-Care Diagnostics. Front. Cell. Infect. Microbiol. 2021, 11, 663949. [CrossRef] [PubMed]

44. Di Paola, N.; Sanchez-Lockhart, M.; Zeng, X.; Kuhn, J.H.; Palacios, G. Viral genomics in Ebola virus research. Nat. Rev. Microbiol. 2020, 18, 365-378. [CrossRef]

45. McLaren, P.J.; Fellay, J. HIV-1 and human genetic variation. Nat. Rev. Genet. 2021, 22, 645-657. [CrossRef] [PubMed]

46. Bordigoni, A.; Motte, A.; Tissot-Dupont, H.; Colson, P.; Desnues, C. Development and validation of a multiplex qPCR assay for detection and relative quantification of HPV16 and HPV18 E6 and E7 oncogenes. Sci. Rep. 2021, 11, 4039. [CrossRef] [PubMed]

47. Hattakam, S.; Elong Ngono, A.; McCauley, M.; Shresta, S.; Yamabhai, M. Repeated exposure to dengue virus elicits robust cross neutralizing antibodies against Zika virus in residents of Northeastern Thailand. Sci. Rep. 2021, 11, 9634. [CrossRef]

48. Labib, M.; Philpott, D.N.; Wang, Z.; Nemr, C.; Chen, J.B.; Sargent, E.H.; Kelley, S.O. Magnetic Ranking Cytometry: Profiling Rare Cells at the Single-Cell Level. Acc. Chem. Res. 2020, 53, 1445-1457. [CrossRef]

49. Wang, Z.; Gagliardi, M.; Mohamadi, R.M.; Ahmed, S.U.; Labib, M.; Zhang, L.; Popescu, S.; Zhou, Y.; Sargent, E.H.; Keller, G.M.; et al. Ultrasensitive and rapid quantification of rare tumorigenic stem cells in hPSC-derived cardiomyocyte populations. Sci. Adv. 2020, 6, eaay7629. [CrossRef]

50. Aldridge, P.M.; Mukhopadhyay, M.; Ahmed, S.U.; Zhou, W.; Christinck, E.; Makonnen, R.; Sargent, E.H.; Kelley, S.O. Prismatic Deflection of Live Tumor Cells and Cell Clusters. ACS Nano 2018, 12, 12692-12700. [CrossRef]

51. Mair, B.; Aldridge, P.M.; Atwal, R.S.; Philpott, D.; Zhang, M.; Masud, S.N.; Labib, M.; Tong, A.H.Y.; Sargent, E.H.; Angers, S.; et al. High-throughput genome-wide phenotypic screening via immunomagnetic cell sorting. Nat. Biomed. Eng. 2019, 3, 796-805. [CrossRef]

52. Parvez, S.; Herdman, C.; Beerens, M.; Chakraborti, K.; Harmer, Z.P.; Yeh, J.-R.J.; MacRae, C.A.; Yost, H.J.; Peterson, R.T. MIC-Drop: A platform for large-scale in vivo CRISPR screens. Science 2021, 373, 1146-1151. [CrossRef]

53. Elowitz, M.B.; Leibler, S. A synthetic oscillatory network of transcriptional regulators. Nature 2000, 403, 335-338. [CrossRef] [PubMed]

54. Henningsen, J.; Schwarz-Schilling, M.; Leibl, A.; Gutiérrez, J.; Sagredo, S.; Simmel, F.C. Single Cell Characterization of a Synthetic Bacterial Clock with a Hybrid Feedback Loop Containing dCas9-sgRNA. ACS Synth. Biol. 2020, 9, 3377-3387. [CrossRef] [PubMed]

55. Li, S.; Jendresen, C.B.; Grünberger, A.; Ronda, C.; Jensen, S.I.; Noack, S.; Nielsen, A.T. Enhanced protein and biochemical production using CRISPRi-based growth switches. Metab. Eng. 2016, 38, 274-284. [CrossRef] [PubMed]

56. Camsund, D.; Lawson, M.J.; Larsson, J.; Jones, D.; Zikrin, S.; Fange, D.; Elf, J. Time-resolved imaging-based CRISPRi screening. Nat. Methods 2020, 17, 86-92. [CrossRef] [PubMed]

57. Kong, T.; Backes, N.; Kalwa, U.; Legner, C.; Phillips, G.J.; Pandey, S. Adhesive Tape Microfluidics with an Autofocusing Module That Incorporates CRISPR Interference: Applications to Long-Term Bacterial Antibiotic Studies. ACS Sens. 2019, 4, $2638-2645$. [CrossRef] [PubMed]

58. Han, X.; Liu, Z.; Zhao, L.; Wang, F.; Yu, Y.; Yang, J.; Chen, R.; Qin, L. Microfluidic Cell Deformability Assay for Rapid and Efficient Kinase Screening with the CRISPR-Cas9 System. Angew. Chem. Int. Ed. 2016, 55, 8561-8565. [CrossRef] 